\title{
High Strain Rate Response of Nanofiber Interlayered Structural Composites
}

Elif Özden-Yenigün ${ }^{*}$, Kaan Bilge $e^{2}$ Emin Sünbüloğlu ${ }^{3}$ Ergun Bozdağ $\breve{g}^{3}$, Melih Papila $^{2}$

${ }^{1}$ Istanbul Technical University, Department of Textile Engineering, 34437, Istanbul, Turkey

${ }^{2}$ Sabanci University, Materials Science and Nano-Engineering Program, 34956, Istanbul, Turkey

${ }^{3}$ Istanbul Technical University, Department of Mechanical Engineering, 34437, Istanbul, Turkey

* Corresponding author: ozdenyenigun@itu.edu.tr

KEYWORDS: Electrospinning, nanofibers, Split Hopkinson pressure bar, interlayer, high strain rate deformation, toughening

\begin{abstract}
Nanofibrous interlayer toughening strategy for laminated composite materials typically demonstrated at quasi-static loading is here evaluated under high strain rate deformation.

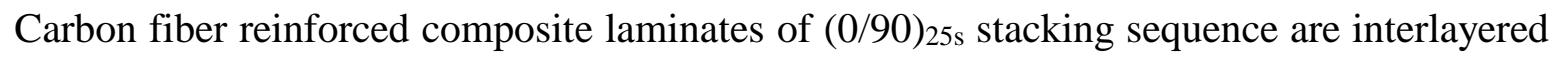
by $\mathrm{P}(\mathrm{St}-\mathrm{co}$-GMA) nanofibers which are chemically tuned for interfacial compatibility when embedded in epoxy matrix. The cubical composite specimens are cut and subjected to high strain-rate deformation via Split Hopkinson pressure bar testing. Specimens are hit at their through-the-thickness (stacking) and side-to-side (in-plane) directions. The change in the dissipation of energy due to altered interlaminar microstructure is monitored and reported. Enhancement in the capacity of the energy dissipation due to the nanofibrous interlayers is as high as $80 \%$ in-plane and $40 \%$ through thickness directions, depending on the strain rate.
\end{abstract}


The results overall suggest that interlayer toughening strategy used in this work prevents the formation of critical matrix cracks that can cause the formation of instantaneous mode II delamination. Incorporation of the nanofibers without causing notable weight penalty effectively toughen the matrix dominant interlaminar zones under high strain rate conditions as well.

\section{Introduction}

Several toughening strategies for structural laminated composites focus basically on reinforcing the interlaminar regions between two subsequent plies. These thin interfacial regions are relatively resin-rich, but exhibit different properties than the bulk resin depending on the matrix itself and the ply-interface interaction which is affected by the fiber-phase architecture, orientation and lamination sequence [1]. Addition of sub-phases into the interlaminar planes have typically been proposed to avoid/delay extensive interply crack propagation and to prevent subsequent formation of interply delamination. They can be in the form of dispersed particles[2-4], films [5-7], fibrous/nanofibrous reinforcements [8-12] and their combinations [9, 13]. Moreover, recent studies by Daelemans et. al specifically defined the effect of reinforcement morphology (either as a film, nanofibrous mats or particulates) on the unique mechanical performance $[14,15]$. This approach is referred as interlayer toughening in general [16]. The challenge has been to adapt the interlayer toughening strategies into the conventional materials and manufacturing techniques while aiming for both enhanced in-plane and out-of-plane mechanical behavior. In this regard, the nanofibrous interleaf/interlayer toughening is arguably more promising compared to the other sub-phase choices. Recent studies [8-10, 13-15, 17-20] demonstrated 
the potent of the nano and sub-micron sized fibrous interlayers to toughen the laminated composites. Our earlier and current work more focused on surface modified/reactive polystyrene-co-glycidyl methacrylate $\mathrm{P}(\mathrm{St}-\mathrm{co}$-GMA).polymer on carbon/epoxy prepreg systems both under in-plane and out-of-plane loading conditions at the macro-scale [13].

Along with the out of plane and in-plane quasi-static performance, behavior of laminated composites under high strain rates is also intriguing, and especially crucial for their contribution against impact. There have been extensive efforts for the dynamic behavior of the conventional composite formations along with the other engineering materials [21]. Although such high strain rate phenomena have been extensively studied in conventional materials, such as metals, ceramics, polymers and conventional composite formations [2143], to date the mechanical deformation of such interlayer toughened composites under large strains and at high strain rates has not been directly studied. Besides, there are even limited attempts to reveal the fracture behavior of layered structural composites [21, 29, 33$35,42]$ and nanocomposites $[44,45]$ at high strain rates. On the other hand, published data and associated knowledge on high strain rate mechanical deformation of nanofiberinterlayer toughened composites appear to be lacking. As such, the contributions of nanoscale morphologies and toughened interfaces to the high strain rate characteristics are yet to be thoroughly explored. To the best of our knowledge, investigations specific to the high strain rate deformation of nanofiber interlayered structural composites for the development of new protective materials are still needed.

This study attempts to reveal the effects of nanofibrous interlayers at high strain rate. The research hypothesis states that exceptional mechanical performances of nanofibrousinterlayered structural composites are not limited at quasi-static rates, but also lead to the 
superior properties of these composites at high deformation rates. That is, performance of these nanofibrous interlayers in the structural composites under the extreme condition of high deformation rates and to large strains complements their proven advantages in increasing the resistance to delamination and transverse matrix cracking. As a continuation of our earlier work $[8,9,13,17]$, lab synthesized surface modified/reactive polystyrene-coglycidyl methacrylate P(St-co-GMA) nanofibers with epoxide functional groups were used. The carbon fiber reinforced composite laminates' of $(0 / 90)_{25 s}$ stacking sequence were interlayered by these nanofibers. The experimental plan employed split Hopkinson pressure bar (SHPB) test both through fiber and transverse to fiber directions to examine the mechanical characteristics of composite structures evolving with the strain rates and the dynamic characteristics of the nanofibrous interlayers as their effects on the dissipated energy and ultimate compressive strength. The nanofibrous interlayers were examined by their effects on the dissipated energy and ultimate compressive strength of composite structures subject to the various strain rates.

\section{Materials and Methods}

\subsection{Electrospinning of P(St-co-GMA) Nanofibers and laminate manufacturing:}

The procedure for the synthesis of $\mathrm{P}(\mathrm{St}-\mathrm{co}-\mathrm{GMA})$ (Figure 1) with 10 wt.\% GMA content was explained in detail in our previous works $[8,9,13,17]$. Polymer solutions were prepared by dissolving P(St-co-GMA) 30 wt.\% in DMF and stirring for $3 \mathrm{hr}$. Applied voltage, solution flow rate and tip to ground distance were set at $15 \mathrm{kV}, 30 \mu \mathrm{L} / \mathrm{h}$ and $10 \mathrm{~cm}$, respectively during the electrospinning. The polymer solution was electrospun directly onto 
the carbon/epoxy prepreg layers (Aldila Composites, 34-700 (24k)-AR2527). Consequently, a thin homogenous layer of nanofibers (mean fiber diameter of $400 \mathrm{~nm}$ ), was deposited on the prepreg surface forming the interlayer with an additional weight as low as $0.1 \%$ of the prepreg ply weight. For Split-Hopkinson bar tests, the specimen thickness of $10 \mathrm{~mm}$ was to be aimed which ultimately required the lamination of 100 subsequent prepreg plies that each forming 99 interlaminar region to be toughened. In order to decrease the electrospinning process time, we have firstly stacked each (0/90) plies and and carried out the electrospinning only over these $90^{\circ}$ plies. Hence each specimen with $(0 / 90)_{25 \text { s lay-up }}$ sequence contained 49 toughened interlaminar regions.

After stacking the plies for intended laminates, each stack was put on a metallic tooling plate along with a release film and peel ply. Another sheet of peel ply was then laid on the pile of plies followed by a nonwoven breather layer. Next, the whole lay-up was vacuum bagged and kept under vacuum during the cure cycle. Prepreg stacks were cured at $100^{\circ} \mathrm{C}$ and so the glass transition temperature of $\mathrm{P}(\mathrm{St}-\mathrm{co}-\mathrm{GMA})$ copolymer fibers which is also around $100{ }^{\circ} \mathrm{C}$ was not exceeded [8]. Cured $10 \mathrm{~mm}$ thick laminates were cut into $10 \mathrm{~mm} \mathrm{x}$ $10 \mathrm{~mm}$ x $10 \mathrm{~mm}$ cubic SHPB specimens by waterjet.

\subsection{Compressive Split-Hopkinson Pressure Bar (SHPB) apparatus}

The standard compressive-type SHPB apparatus as shown in Figure 2a was used in this study. The main parts of the compressive SHPB apparatus are: propelling mechanism, striker, incident bar, transmitter bar and support stand. The diameter of the incident and transmitter bars is $22.2 \mathrm{~mm}$ and the length is $1510 \mathrm{~mm}$. The bars are made of Maraging-350

High Strength Steel which has Young's modulus of $210 \mathrm{GPa}$ and density of $8100 \mathrm{~kg} / \mathrm{m}^{3}$. 
The specimen is positioned between the incident and transmitter bars (see the inset in Figure 2a). Prior to the testing, $3 \mathrm{M}^{\mathrm{TM}}$ paper tape are attached to the impact face of incident bar as a practical pulse-shaper. When the striker hits the incident bar, an elastic stress pulse is generated and travels along the incident bar [46]. Once the compressive strain pulse $\left(\varepsilon_{i}\right)$ reaches the specimen-incident bar interface, due to the mismatch between their impedance values, some portion of the strain pulse is reflected back $\left(\varepsilon_{r}\right)$ into the incident bar. The other part of the pulse is transmitted through the specimen into the transmitter bar $\left(\varepsilon_{t}\right)$. Strain gages mounted on the incident and transmitter bars are used to collect and resolve the strain-wave signals. The $1^{\text {st }}$ gage on the incident bar measures both the incident and reflected pulses whereas the $2^{\text {nd }}$ strain gage on the transmitter bar merely measures the transmitted pulse. The output of the strain gages is fed through Wheatstone-Bridge circuit into a digital storage oscilloscope, where the signals are digitized and stored at a sampling rate of $400 \mathrm{kHz}$ on a PC.

Lindholm [47] gives the expression for stress predictions in terms of the measured strain pulses. The stresses on the loaded front face (Eq 1) and rear face (Eq 2) of the specimen are calculated as:

$$
\begin{aligned}
\sigma_{\mathrm{sfi}} & =\left[E_{0} \frac{A_{0}}{A_{S}}\right]\left(\varepsilon_{\mathrm{i}}+\varepsilon_{\mathrm{r}}\right) \\
\sigma_{\mathrm{sft}} & =\left[\frac{E_{0} A_{0}}{2 A_{S}}\right]\left(\varepsilon_{\mathrm{i}}+\varepsilon_{\mathrm{r}}+\varepsilon_{\mathrm{t}}\right)
\end{aligned}
$$

where $A_{0}$ and $E_{0}$ refer to the area of the cross-section and modulus of elasticity of the incidence bar, respectively, $\varepsilon$ is the axial strain corresponding to axis of the bar, and indices $t$ and $r$ indicate the recorded transmitted wave in the transmission bar and reflected wave in 
the incident bar, respectively. Considering the specimen to be in axial-force-balance state, $\varepsilon_{t}(t)+\varepsilon_{r}(t)=\varepsilon_{i}(t)$ and then the equation system may be obtained in the form of

$$
\begin{aligned}
& \sigma_{s}(t)=E_{0} \frac{A_{0}}{A_{s}} \varepsilon_{t}(t) \\
& \dot{\varepsilon}_{s}(t)=-2 \frac{c_{0}}{L_{s}} \varepsilon_{r}(t) \\
& \varepsilon_{s}(t)=\int_{0}^{T_{\text {pulse }}} \dot{\varepsilon}_{s}(\tau) d \tau
\end{aligned}
$$

with $c_{0}$ being the velocity of propagation of a longitudinal wave in the bar with a mass density of $\rho_{0}[48]$ defined as $c_{0}=\sqrt{E_{0} / \rho_{0}}$.

Also in [48], the influence of geometry is investigated for non-circular cross sections to check for radial inertia and axial equilibrium assumptions to hold. The ideal slenderness of a non-circular specimen (which is almost a must while testing composites with SHPB systems) is defined by $\lambda=\frac{L}{\sqrt{I / A}}$ and $1.4 \leq \lambda \leq 2.8$ in [48], and for a nominally $10 \mathrm{~mm} \times 10 \mathrm{~mm} \times 10 \mathrm{~mm}$ specimen utilized in this study, the value exhibits a slight deviation, with $\lambda_{s} \approx 3.4$ considering measured sample dimension tolerances. However, smaller specimens are foreseen to introduce higher error leading to loss of continuum assumption as too few repeating (0/90) sub-laminate of carbon fibers exist in the specimen and shorter specimens lead to too high strain rates than observed here, thus, the current geometry has been adopted as an optimum for our purpose of high strain rates (on the order of $10^{3} \mathrm{~s}^{-1}$ ). Also, it should be noted that the derivation in accounts of isotropic/homogeneous material, and indeed may not fully cover the current anisotropic case [48]. 
Dimensions of each specimen were measured before the test. The test conditions were also recorded. The specimen stress-strain curve, and the strain-rate of each test were adopted using the initial set of pulses. Dissipated energy values for each test were also calculated. Specimens after the tests were kept for further scanning electron microscopy (SEM) analysis. The SHPB system was calibrated initially to account of the strain-gage positions away from the specimen interfaces. A sample of stress-strain data and strain-rate of the tests are given in Figure 2b. Each test associated with the types of specimen/loading (for instance, interlayered/impact through-the-thickness) was repeated at least 5 times for data analysis.

\section{RESULTS AND DISCUSSION}

The effect of interlayers on ultimate compressive strength and dissipated energy was investigated. Reference carbon fiber reinforced composite laminates with $(0 / 90)_{25 \text { s lay-up }}$ sequences and the laminates interlayered by $\mathrm{P}(\mathrm{St}-\mathrm{co}-\mathrm{GMA})$ nanofibers were subject to high strain-rate deformation in through-the-thickness and side-to-side (in-fiber-plane) directions. Furthermore, fiber-matrix interface strengthening mechanism and its influence on strength and dissipated energy were also explored by varying the strain rates. As the strain rate is sensitive to the entry gas barrel pressure (impact pressure of the striker on the input bar), it was alternated at 2, 4 and 6 bar which corresponds to the strain rates of $2600 \mathrm{~s}^{-1}, 3500 \mathrm{~s}^{-1}$, $4000 \mathrm{~s}^{-1}$, respectively (see Figure 3a). Two high-speed cameras were mounted to monitor the failure modes of the reference/neat and nano-interlayered composite laminates with $(0 / 90)_{50 s}$ lay-up sequences, as seen in Figure 3b. Post-SEM analyses were used to trace the interface strengthening mechanism at the fracture surfaces. 


\subsection{Effects of Nanofiber Interlayers on High Strain Rate Stress-Strain Responses and}

\section{Progressive Damage}

The composite specimens tested through-the-thickness and longitudinally (in-fiberdirection) directions, as illustrated in Figure 4. First, engineering stress and strain were measured until failure through-the-thickness direction (Figure 5a) where the high strain rate tests were conducted using a split Hopkinson bar at 4 bars which corresponds to strain rate of $3500 \mathrm{~s}^{-1}$ (Figure 5b). Figure 5a clearly demonstrated that incorporation of the nanofibers increases the ultimate compressive strength by about $13 \%$ without worthy to note weight penalty (which is as low as $0.1 \%$ ). Moreover, much higher energy (see Table 1) was dissipated through the thickness due to the presence of the surface reactive nanofibers between the plies.

Tarfaoui et al. [42] studied the effect of the reinforcing fiber orientation on mechanical properties of the laminated polymer composites subjected to out-of-plane high strain rate compressive loadings. They stated that damaging mode in composite laminates with

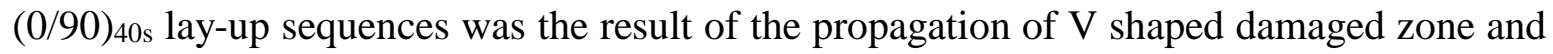
subsequently forming macro-cracks led to failure. In nanofiber interlayered composites, improvement at the high strain rate can also be attributed to retardation of the formation and propagation of cracks by the presence the polymeric nanofibers between each plies in-line with the quasi-static behavior [13]. As seen in Figure 5a, stress versus strain curves were initially linear, and then to gradually became nonlinear up to the ultimate failure stress. Haque et al. [29] explained that the nonlinearity observed in the stress-strain plots results from the matrix-cracking and debonding. Same characteristics can also be noted in Figure $5 \mathrm{a}$, as such the failure of the specimens is attributed to the macro-cracks and debonding due 
to out-of-plane loading. This behavior is also highlighted in post fracture analysis section. In order to examine the extent of damage during the dynamic compression, high-speed photography was used to follow the damage in the samples, as seen in Figure 3b. Figure 6 shows progressive damage of nanofiber interlayered $(0 / 90)_{25 s}$ composites with applied load in the thickness direction at strain rate of $2600 \mathrm{~s}^{-1}$, the images are taken from Camera 1 .

In supporting information (supporting videos 1-4), real-time video of both neat/reference and nanofiber interlayered $(0 / 90)_{25 s}$ composites are also provided in both directions. The reference $(0 / 90)_{25 s}$ composite specimens break into individual ply pieces, this leads to extensive matrix cracking and resulting extensive fiber splitting, and debonding [29]. Thus, the composites without the interlayer toughening exhibit lower ultimate compressive strength and dissipation energy at all strain rates (Table 1). As seen in Figure 6 (Camera 1) and Figure 7 (Camera 2), plies are attached much stronger in the case of nanofiber interlayered composites compared to reference specimens. Stronger interfacial bonding provides higher ultimate compressive strength ( up to 13\%) in the layer-to-layer direction. Ply-block fragmentation was observed in nanointerlayered specimens, and led to delayed matrix cracking in the failure process. The observations suggest that the nanofibers incorporated at the ply-interfaces assist energy dissipation during high rate damage progression and cause higher ultimate compressive failure strength. Haque et al. [29] also noted that the failure mode in through the thickness direction was mostly matrix dominant. Neat and nanofiber interlayered (0/90) 25 s composites were also tested subject to in-plane loading (loading is in-plane of the plies) to examine the matrix cracks and delamination which occur in the privileged interlaminar planes for this loading direction [42]. Figure 8 shows the stress-strain $(\sigma-\varepsilon)$ plots of neat and nanofiber interlayered $(0 / 90)_{25 s}$ composites 
in-plane loading at strain rate of $3500 \mathrm{~s}^{-1}$. Compared to Figure 5a, it is clear that for out-ofplane plane tests, both neat and nanofiber interlayered composites show greater ultimate strength and dissipation energy values. However, for the in-plane loading, the effect of nanofibers on ultimate compressive strength, failure strain and failure mechanism was much more remarkable. The compressive failure strength and the failure strains increased by almost $40 \%$ and $15 \%$, respectively. Furthermore, the stress-strain $(\sigma-\varepsilon)$ plots in Figure 8 were almost linear up to the maximum failure stress since the failure mode is primarily fiber dominant [29].

Progressive damage of the neat and nanofiber interlayered (0/90) $)_{0 \mathrm{~s}}$ composites for in-plane loading at strain rate of $3500 \mathrm{~s}^{-1}$, were monitored via Camera $1 \& 2$, as depicted in Figure 9 (a) and (b). When analyzed framewise through the recorded progression, as in Figure 9 (a) the initial form of damage occurring in neat laminates under in-plane compression was random matrix cracking either forming inside $90^{\circ}$ plies or at $0 / 90$ interlaminar regions. We should note that this damage formation was recorded as the progressive formation of random voids inside the specimens. The ultimate final failure of neat laminates was due to extensive delamination initiated from appearing matrix cracks. Nevertheless, the matrix crack formation and sudden catastrophic delamination behavior can be partly prevented by interlayer addition. Interlayered laminates have rather gone through layer kinking and layer compression resulting in delayed matrix cracking and micro-buckling in the failure process, as seen in Figure 9b. Thus, interlayered nanofibers resisted void-like formation between the plies, resulting in increased ultimate compressive strength and failure strain. 


\subsection{Effects of Strain Rate on Stress-Strain Responses of Nanofiber Interlayered Composites}

Strain rate dependency of ultimate strength and failure strain of laminated composites under compressive dynamic loading was shown, [42] but full understanding of the effect of strain rate not has not been established. This is arguably due to the different initiation and propagation of failure mechanisms in different the fiber types and architectures such as unidirectional and woven composites. Kara et. al. [33] expressed that the modulus and maximum stress of the $( \pm 45)$ symmetric E-glass/polyester composites increased with increasing strain rate. Yokoyama et. al. [21] pointed that the strain rate-ultimate compressive strength correlation was positive for the plain-weave glass/epoxy laminated composite, but negative for the cross-ply and plain-weave carbon/epoxy laminated composites whereas the ultimate compressive strain for all three laminated composites decreased marginally with the increasing strain rate.

The effect of strain rate on stress-strain responses of nano-interlayered composites was explored, to our knowledge for the first time. Through thickness and in-plane directions focused testing were carried out as seen in Figure 10a and Figure 10b, respectively. Results suggest that absorbed energy for both the reference/neat and nanointerlayered composites increased marginally with increasing strain rate (See Table 1). In addition, for the out-ofplane testing, neat and nanointerlayered composites demonstrated much greater ultimate strength and dissipation energy. In relevance, Tarfaoui et al. [42] expressed that the most pronounced effect of increasing the strain rate is the changes in the failure modes. All in all, composite specimens failed by fiber kinking at low rates while delamination and interfacial separation dominated at the higher strain rates [42]. Thus, the variations in ultimate strain 
pointed out different failure mechanisms depending on the strain rate, where laminated composites exhibited significant nonlinear and strain dependent behavior.

\subsection{Post Fracture Analysis}

Fracture of the neat laminates under high strain loading was explosive. All of the tested laminates were instantaneously burst apart into very small dust like particles. Hence no surfaces suitable for fractography were left to collect. On the other hand, interlayered specimens responded to the high pressure loading such that chunks of the cubic specimens have remained intact for which fracture surfaces can be accessible. As the interlayer toughening strategy was to introduce nanofibrous interlayers between each (0/90) block, interlayered specimens contained untoughened regions. Figure 11a and b corresponds to an untoughened 0-90 interlaminar region where the two plies were separated with a clear delamination onset. The damage propagation in that plane caused the formation of hackle markings of the epoxy matrix, typical for Mode II fracture events. Experimental observations suggest that the sudden high strain loading of the neat laminates caused extensive delamination followed by instantaneous compressive fiber and resin fracture. On the other hand, Figure 11c and d show the interlayer toughened (90-0) ply interface where the resin morphology was highly altered due to the nanofibers/epoxy impregnation, forming nanocomposite interlayer. No hackle markings were found on the failure surfaces of the interlayer. This observation suggests the nanofibrous interlayers played a significant role in preventing severe delamination formation and helped the specimens to partially remain intact rather than bursting apart in contrast to the untoughened specimens. Furthermore, Figure 11e shows a fracture zone of a laminate where the fractured resin and reinforcing 
carbon fiber phases as well as the polymer nanofibers are clearly visible. Interconnected sight of the nanofibrous mat between fractured resin chunks also underlined their significant role in matrix/interlayer toughening even under high strain loading conditions.

\section{Conclusion}

High strain rate response of the carbon fiber reinforced composite laminate of $(0 / 90)_{25 \mathrm{~s}}$ stacking sequence and its toughened counterpart by $\mathrm{P}(\mathrm{St}-\mathrm{co}$-GMA) nanofibrous interlayers were investigated both for in-plane and through the thickness loadings via SHPB. The compressive stress-strain behavior of the laminates was shown to be strain rate sensitive. Nanofibrous interlayered laminate was superior in regard to the through-the-thickness compressive characteristics at all high rates of strain tested in this study. Through-thethickness, reference $(0 / 90)_{25 s}$ composite specimens broke into individual ply pieces caused by extensive matrix failure leading to delamination and fiber fracture. Whereas block-ofplies fragmentation was observed in nanointerlayered specimens due to stronger and tougher interlaminar bonding, resulting in suppression of matrix cracking and subsequent failure events. At the in-plane loading, the effect of nanofibers on ultimate compressive strength, failure strain and failure mechanism was much more remarkable, enhancement in the energy dissipation due to the nanofibrous interlayers is as high as $80 \%$ whereas $40 \%$ improvement was also recorded through thickness directions. Interlayer nanofibers are concluded to be resistive against crack formation between the plies, resulting in increased ultimate compressive strength and failure strain.

\section{Supporting Information Available.}




\section{ACKNOWLEDGEMENT}

The authors thank to Sassan Jahangiri and Ayça Ürkmez for their help in electrospinning. 


\section{REFERENCES}

[1] Tsotsis TK. Interlayer Toughening of Composite Materials. Polymer Composites. 2009;30:70-86.

[2] Pham S, Burchill PJ. Toughening of Vinyl Ester Resins with Modified Polybutadienes. Polymer. 1995;36:3279-85.

[3] Huang YJ, Horng JC. Effects of thermoplastic additives on mechanical properties and glass transition temperatures for styrene-crosslinked low-shrink polyester matrices. Polymer. 1998;39:3683-95.

[4] Warrior NA, Turner TA, Robitaille F, Rudd CD. The effect of interlaminar toughening strategies on the energy absorption of composite tubes. Composites Part a-Applied Science and Manufacturing. 2004;35:431-7.

[5] Ishai O, Rosenthal H, Sela N, Drukker E. Effect of Selective Adhesive Interleaving on Interlaminar Fracture-Toughness of Graphite Epoxy Composite Laminates. Composites. 1988; 19:49-54.

[6] Carlsson LA, Aksoy A. Analysis of Interleaved End-Notched Flexure Specimen for Measuring Mode-Ii Fracture-Toughness. International Journal of Fracture. 1991;52:67-77.

[7] Khan SU, Kim JK. Improved interlaminar shear properties of multiscale carbon fiber composites with bucky paper interleaves made from carbon nanofibers. Carbon. 2012;50:5265-77.

[8] Ozden E, Menceloglu YZ, Papila M. Engineering Chemistry of Electrospun Nanofibers and Interfaces in Nanocomposites for Superior Mechanical Properties. Acs Applied Materials \& Interfaces. 2010;2:1788-93.

[9] Ozden-Yenigun E, Menceloglu YZ, Papila M. MWCNTs/P(St-co-GMA) Composite Nanofibers of Engineered Interface Chemistry for Epoxy Matrix Nanocomposites. Acs Applied Materials \& Interfaces. 2012;4:777-84.

[10] Kim JS, Reneker DH. Mechanical properties of composites using ultrafine electrospun fibers. Polymer Composites. 1999;20:124-31.

[11] Dzenis Y. Materials science - Structural nanocomposites. Science. 2008;319:419-20.

[12] Palmeri MJ, Putz KW, Ramanathan T, Brinson LC. Multi-scale reinforcement of CFRPs using carbon nanofibers. Composites Science and Technology. 2011;71:79-86.

[13] Bilge K, Ozden-Yenigun E, Simsek E, Menceloglu YZ, Papila M. Structural composites hybridized with epoxy compatible polymer/MWCNT nanofibrous interlayers. Composites Science and Technology. 2012;72:1639-45.

[14] Daelemans L, van der Heijden S, De Baere I, Rahier H, Van Paepegem W, De Clerck K. Damage-Resistant Composites Using Electrospun Nanofibers: A Multiscale Analysis of the Toughening Mechanisms. Acs Applied Materials \& Interfaces. 2016;8:11806-18.

[15] van der Heijden S, Daelemans L, De Schoenmaker B, De Baere I, Rahier H, Van Paepegem W, et al. Interlaminar toughening of resin transfer moulded glass fibre epoxy laminates by polycaprolactone electrospun nanofibres. Composites Science and Technology. 2014;104:66-73. 
[16] Bilge K, Papila M. 10 - Interlayer toughening mechanisms of composite materials A2 Qin, Qinghua. In: Ye J, editor. Toughening Mechanisms in Composite Materials: Woodhead Publishing; 2015. p. 263-94.

[17] Bilge K, Venkataraman S, Menceloglu YZ, Papila M. Global and local nanofibrous interlayer toughened composites for higher in-plane strength. Composites Part a-Applied Science and Manufacturing. 2014;58:73-6.

[18] Magniez K, Chaffraix T, Fox B. Toughening of a Carbon-Fibre Composite Using Electrospun Poly(Hydroxyether of Bisphenol A) Nanofibrous Membranes Through Inverse Phase Separation and Inter-Domain Etherification. Materials. 2011;4:1967-84.

[19] Palazzetti R, Zucchelli A, Gualandi C, Focarete ML, Donati L, Minak G, et al. Influence of electrospun Nylon 6,6 nanofibrous mats on the interlaminar properties of Grepoxy composite laminates. Composite Structures. 2012;94:571-9.

[20] Zucchelli A, Focarete ML, Gualandi C, Ramakrishna S. Electrospun nanofibers for enhancing structural performance of composite materials. Polymers for Advanced Technologies. 2011;22:339-49.

[21] Yokoyama T, Nakai Y. High strain-rate compressive characteristics of carbon/epoxy laminated composites in through-thickness direction. Advances in Experimental Mechanics. 2004;1-2:11-6.

[22] Bi J, Xiao BL, Ma ZY. High strain rate superplastic deformation behavior of powdermetallurgy processed 17\% SiCp/2024 Al composite. Acta Metallurgica Sinica. 2002;38:6214.

[23] Chan KC, Wang CL, Zhang KF. Low temperature and high strain rate superplasticity of Ni-1 mass\% SiC nanocomposite. Materials Transactions. 2004;45:2558-63.

[24] Chen DM, Wang G, Sun JF, Shen J. Deformation behavior of tungsten wires enhanced Zr-based bulk metallic glass composite at high strain rate. Acta Metallurgica Sinica. 2006;42:1003-8.

[25] Goldberg RK, Gilat A. Experimental and computational characterization of the high strain rate tensile response of polymer matrix composites. Composite Materials: Testing and Design, Fourteenth Volume. 2003;1436:207-23.

[26] Goldberg RK, Roberts GD, Gilat A. Incorporation of mean stress effects into the micromechanical analysis of the high strain rate response of polymer matrix composites. Composites Part B-Engineering. 2003;34:151-65.

[27] Greenfield MJ, Hunter TF, Kalika DS, Penn LS. Improvement of interfaces by tethered polymer chains. Part II: Evaluation of a particulate composite at very high strain rate. Journal of Composite Materials. 2001;35:175-86.

[28] Guden M, Hall IW. High strain rate deformation behavior of a continuous fiber reinforced aluminum metal matrix composite. Computers \& Structures. 2000;76:139-44.

[29] Haque A, Ali M. High strain rate responses and failure analysis in polymer matrix composites - An experimental and finite element study. Journal of Composite Materials. 2005;39:423-50.

[30] $\mathrm{Hu} \mathrm{H}$, Zhen LA. High Strain Rate Superplastic Deformation Behavior of TiN(P)/2014Al Composite. Manufacturing Science and Engineering, Pts 1-5. 2010;97101:1633-6. 
[31] Iwasaki H, Mori T, Mabuchi M, Higashi K. Improvement of post-deformation properties by static annealing for a high strain rate superplastic composite. Advances in Engineering Plasticity, Pts 1-2. 2000;177-1:667-72.

[32] Iwasaki H, Yada Y, Mori T, Mabuchi M, Higashi K. Cavitation control by static annealing after deformation at a high strain rate of a Si3N4p/Al-Mg-Si composite. Scripta Materialia. 1996;34:1179-84.

[33] Kara A, Tasdemirci A, Guden M. Modeling quasi-static and high strain rate deformation and failure behavior of a (+/- 45) symmetric E-glass/polyester composite under compressive loading. Materials \& Design. 2013;49:566-74.

[34] Kim W, Argento A, Lee E, Flanigan C, Houston D, Harris A, et al. High strain-rate behavior of natural fiber-reinforced polymer composites. Journal of Composite Materials. 2012;46:1051-65.

[35] Lee OS, Lee JY, Kim GH, Hwang JS. High strain-rate deformation of composite materials using a Split Hopkinson Bar technique. Fracture and Strength of Solids, Pts 1 and 2. 2000;183-1:307-12.

[36] liozberg YR, Hoy RS, Mrozek RA, Lenhart JL, Andzelm JW. Role of entanglements and bond scission in high strain-rate deformation of polymer gels. Polymer. 2014;55:254351.

[37] Luo XT, Yang GJ, Li CJ, Kondoh K. High strain rate induced localized amorphization in cubic $\mathrm{BN} / \mathrm{NiCrAl}$ nanocomposite through high velocity impact. Scripta Materialia. 2011;65:581-4.

[38] Mabuchi M, Iwasaki H, Higashi K. An investigation of shear deformation in a semisolid state of a high strain rate superplastic Si3N4p/Al-Mg-Si composite. Acta Materialia. 1998;46:5335-43.

[39] Mishra RS, Valiev RZ, McFadden SX, Islamgaliev RK, Mukherjee AK. Severe plastic deformation processing and high strain rate superplasticity in an aluminum matrix composite. Scripta Materialia. 1999;40:1151-5.

[40] Niu JT, Han LH, Hu H. High strain rate superplastic deformation of 30 vol.\% ALN(P)/6061Al composite. Hot Deformation of Aluminum Alloys Iii. 2003:193-8.

[41] Salas PA, Benson DJ, Venkataraman S, Loikkanen MJ. Numerical Implementation of Polymer Viscoplastic Equations for High Strain-Rate Composite Models. Journal of Aerospace Engineering. 2009;22:304-9.

[42] Tarfaoui M, Choukri S, Neme A. Effect of fibre orientation on mechanical properties of the laminated polymer composites subjected to out-of-plane high strain rate compressive loadings. Composites Science and Technology. 2008;68:477-85.

[43] Wang LL, Sun ZJ. Studies on rate dependent damage evolution in polymer blends in high strain rates. Plastics Rubber and Composites. 2008;37:246-50.

[44] Demir MM, Horzum N, Tasdemirci A, Turan K, Guden M. Mechanical Interlocking between Porous Electrospun Polystyrene Fibers and an Epoxy Matrix. Acs Applied Materials \& Interfaces. 2014;6:21901-5.

[45] Lee JH, Veysset D, Singer JP, Retsch M, Saini G, Pezeril T, et al. High strain rate deformation of layered nanocomposites. Nature Communications. 2012;3.

[46] Kolsky H. An investigation of the mechanical properties of materials at very high rates of loading. Proceedings of the Physical Society B. 1949;62:676-700. 
[47] U.S. L. Some experiments with the split Hopkinson bar. J Mech Phys Solids. 1964;12:317-35.

[48] Sen O, Tekalur SA, Maity P. On the use of non-cylindrical specimens in a splitHopkinson pressure bar. Journal of Strain Analysis for Engineering Design. 2011;46:86678. 


\section{$\underline{\text { Figure Captions }}$}

Figure 1: Chemical Structure of P(St-co-GMA)

Figure 2: (a) The standard compressive-type SHPB apparatus used in this study (b) A sample of stress-strain data and strain-rate of the tests.

Figure 3: (a) Strain rate evolution depends on impact pressure (b) The illustration of mounted cameras for monitoring progressive damage.

Figure 4: Illustration of interlayered ply sequences whereas the arrows indicated the incident impact direction through the thickness and side-to-side (in-fiber-plane) directions.

Figure 5: (a) Stress-strain $(\sigma-\varepsilon)$ and (b) Strain rate and stress versus time plots of neat

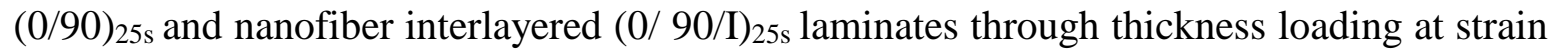
rate of $3500 \mathrm{~s}^{-1}$

Figure 6: Progressive damage of nanofiber interlayered $(0 / 90)_{25}$ s laminates with applied load in thickness direction at strain rate of $2600 \mathrm{~s}^{-1}$, high speed photography images are taken from mounted Camera $1 .(\mathrm{t}=0$, time of impact)

Figure 7. Progressive damage of nanofiber interlayered $(0 / 90)_{25 \text { s }}$ composites with applied load in thickness direction at strain rate of $2600 \mathrm{~s}^{-1}$, high speed photography images are taken from mounted Camera 2 . $(\mathrm{t}=0$, time of impact)

Figure 8. Stress-strain $(\sigma-\varepsilon)$ plots of neat $(0 / 90)_{25 s}$ and nanofiber interlayered $(0 / 90 / \mathrm{I})_{25 \mathrm{~s}}$ composites in-plane loading at strain rate of $3500 \mathrm{~s}^{-1}$

Figure 9. Progressive damage of (a) neat $(0 / 90)_{25 \mathrm{~s}}$ and (b) nanofiber interlayered $(0 / 90 / \mathrm{I})_{25 \mathrm{~s}}$ composites in in-plane loading at strain rate of $3500 \mathrm{~s}^{-1}$, are monitored via Camera 1. 
Figure 10. Stress-strain $(\sigma-\varepsilon)$ plots of nanofiber interlayered $(0 / 90 / \mathrm{I})_{50 \text { s }}$ composites (a) through thickness (out-of-plane) (b) in-plane loading at strain rate of $2600 \mathrm{~s}^{-1}(2 \mathrm{bar}), 3500 \mathrm{~s}^{-}$ 1 (4 bar), $4000 \mathrm{~s}^{-1}(6$ bar $)$.

Figure 11: a,b) Unreinforced 0/90 interface and c,d) Nanofiber reinforced 90/0 interface for interlayered laminates. e) A randomly fractured composite part showing all of the constituents.

\section{$\underline{\text { Table Captions }}$}

Table 1: Strain rate dependencies of neat $(0 / 90)_{25 \mathrm{~s}}$ and nanofiber interlayered $(0 / 90 / \mathrm{I})_{25 \mathrm{~s}}$ composites. Ultimate compressive strength $(\mathrm{MPa})$ and dissipated energy values are reported at both directions. 


\section{FIGURES}

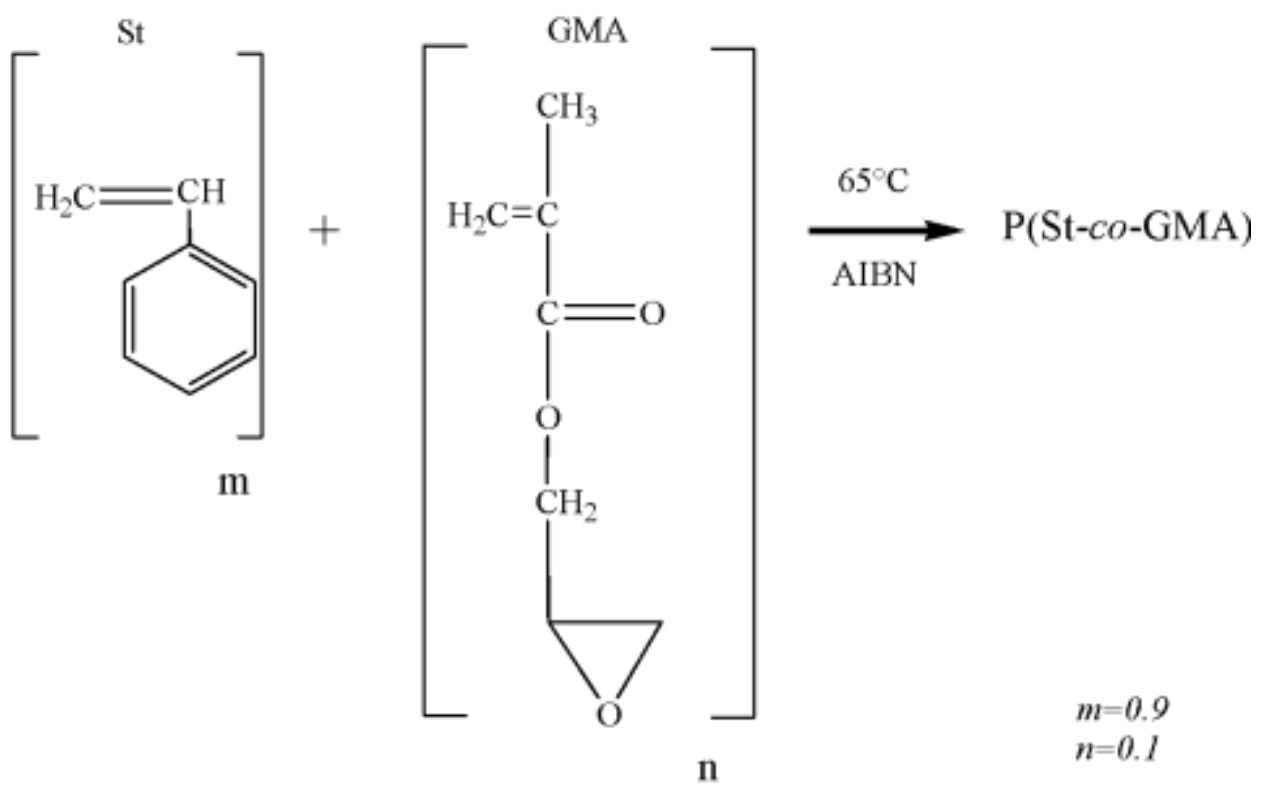

Figure 1. 


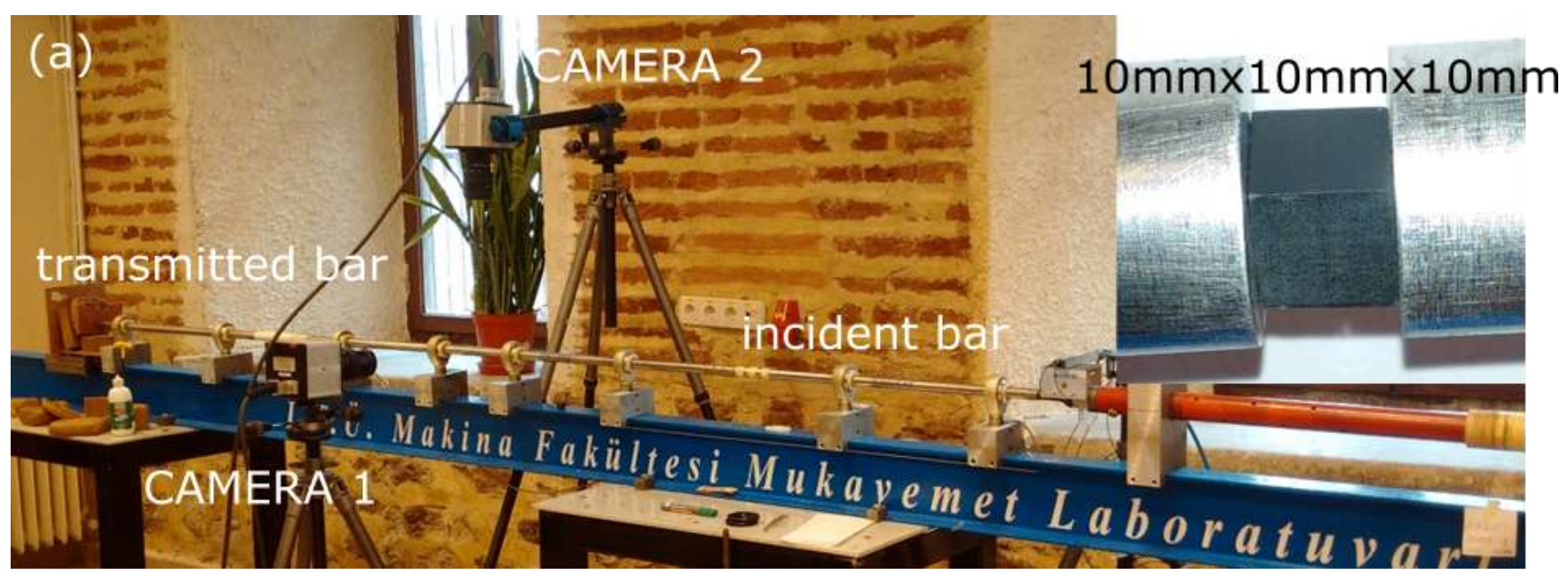

Time (sec)

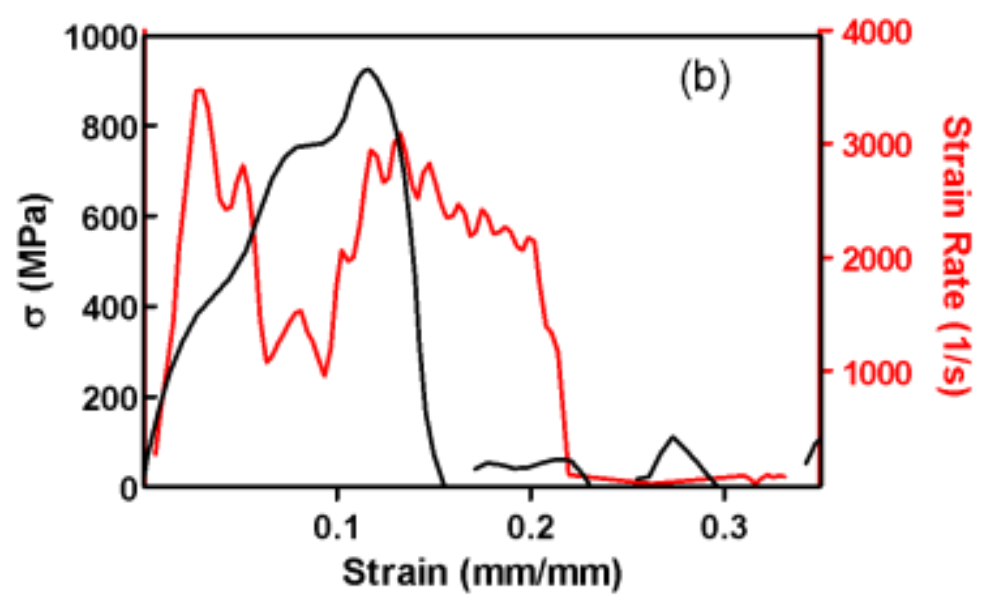

Figure 2. 


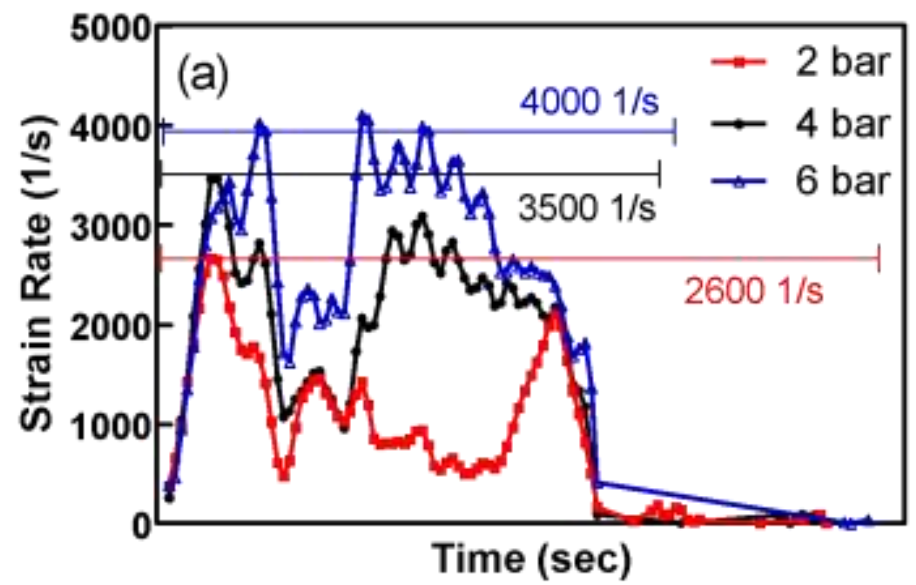

(b)

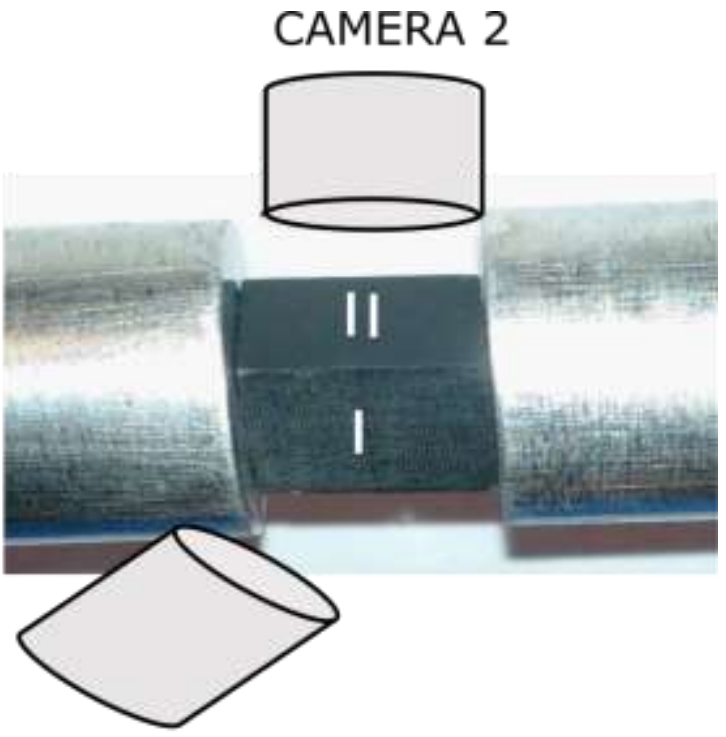

CAMERA 1

Figure 3. 

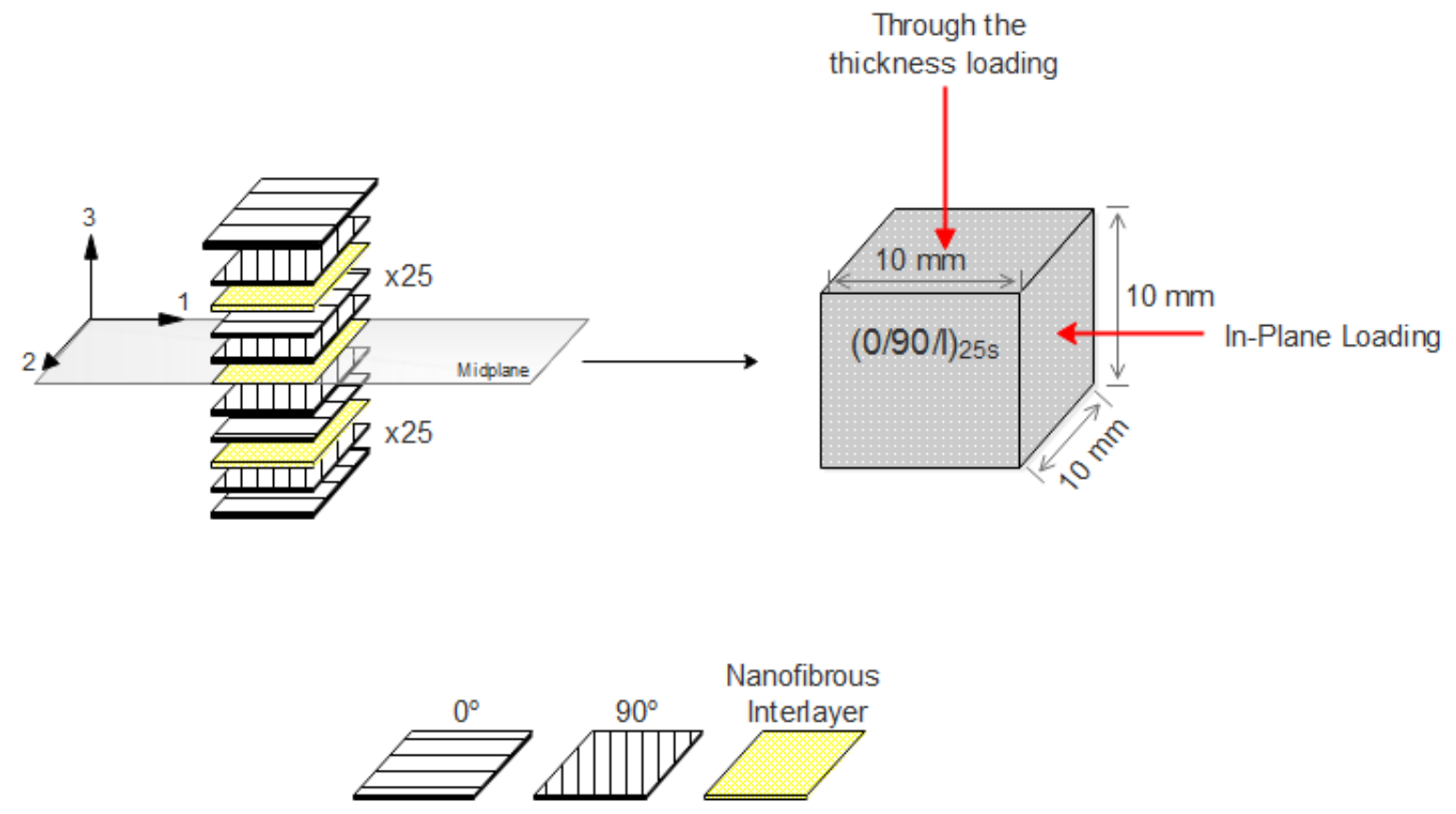

Figure 4. 

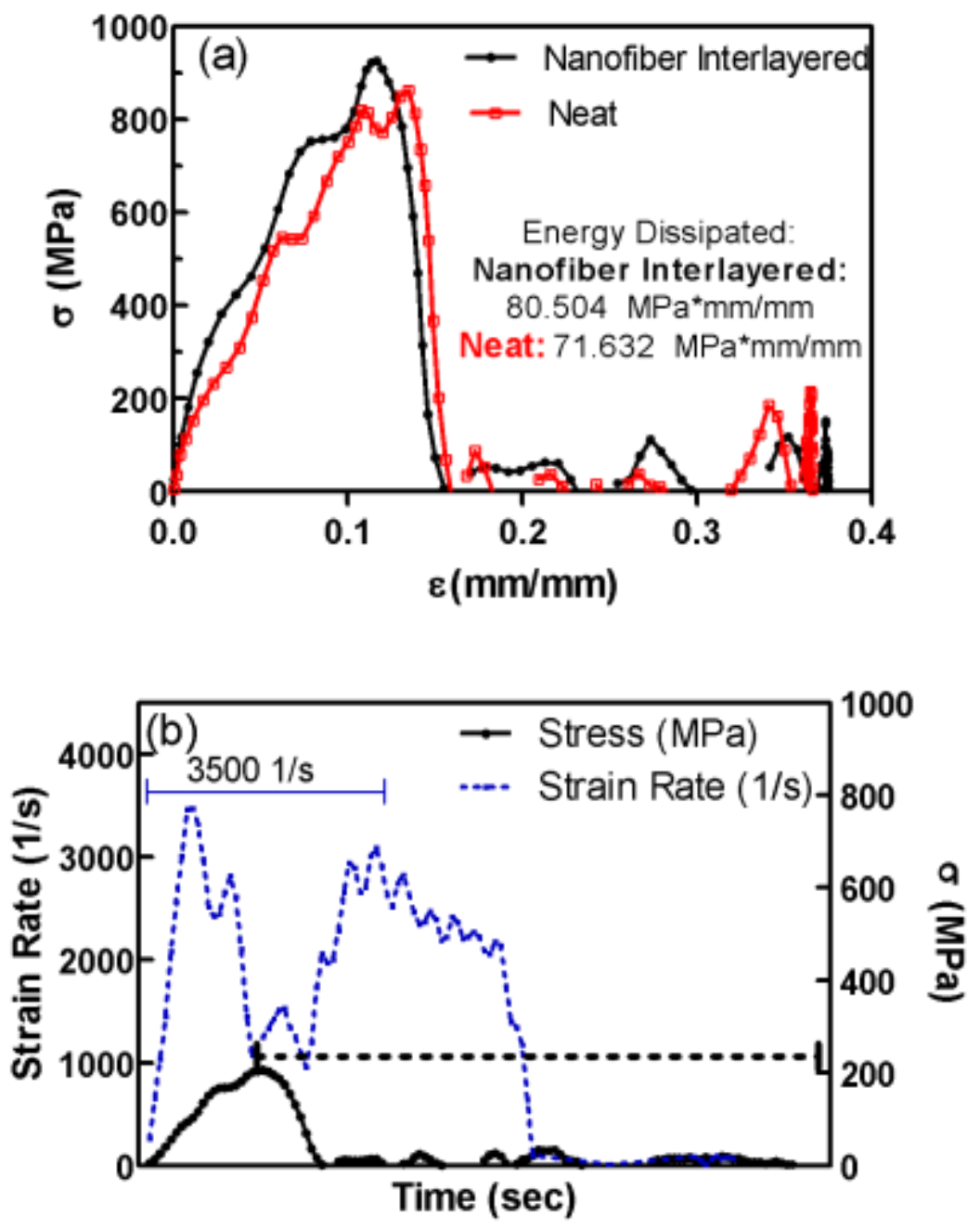

Figure 5. 


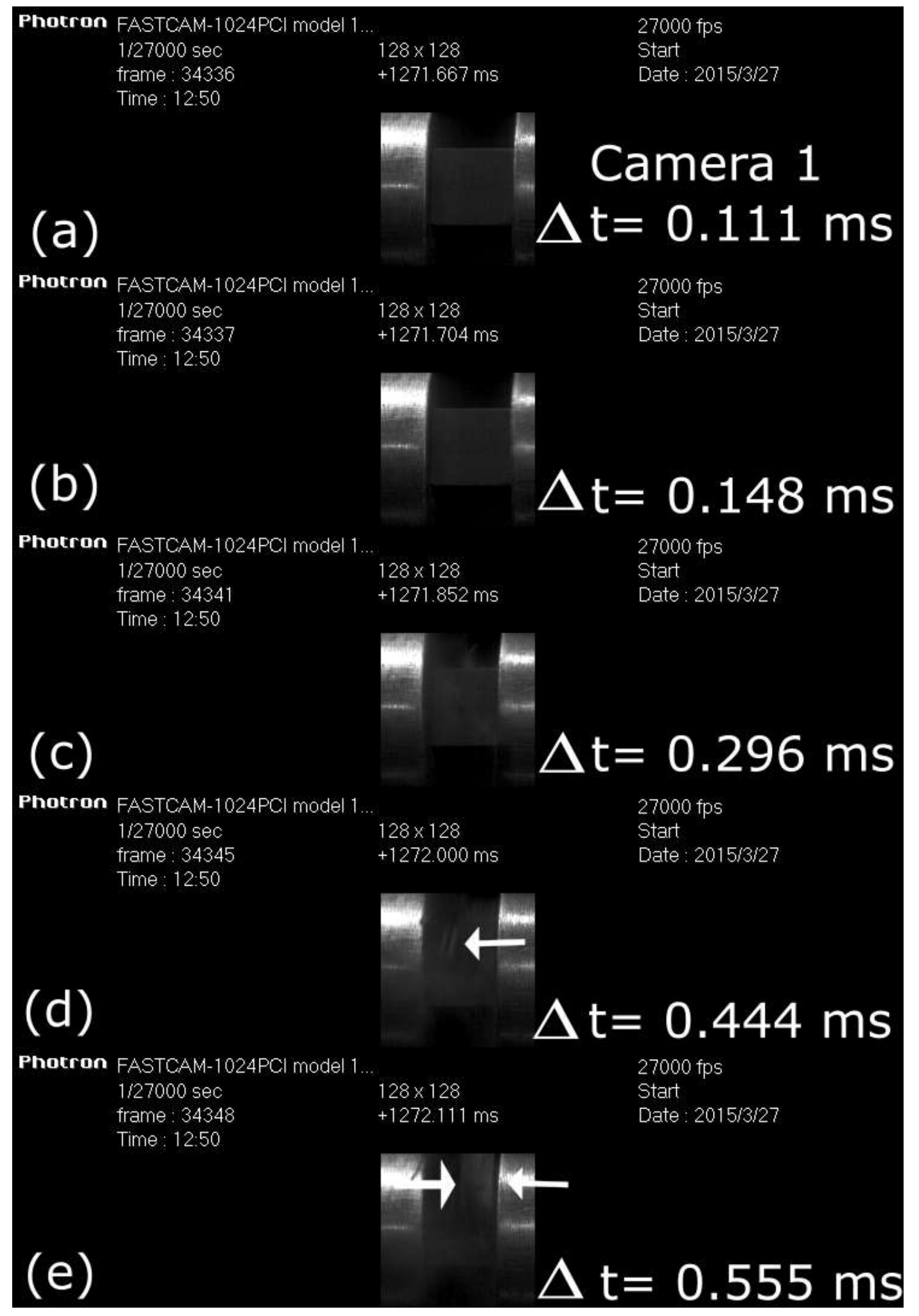

Figure 6. 


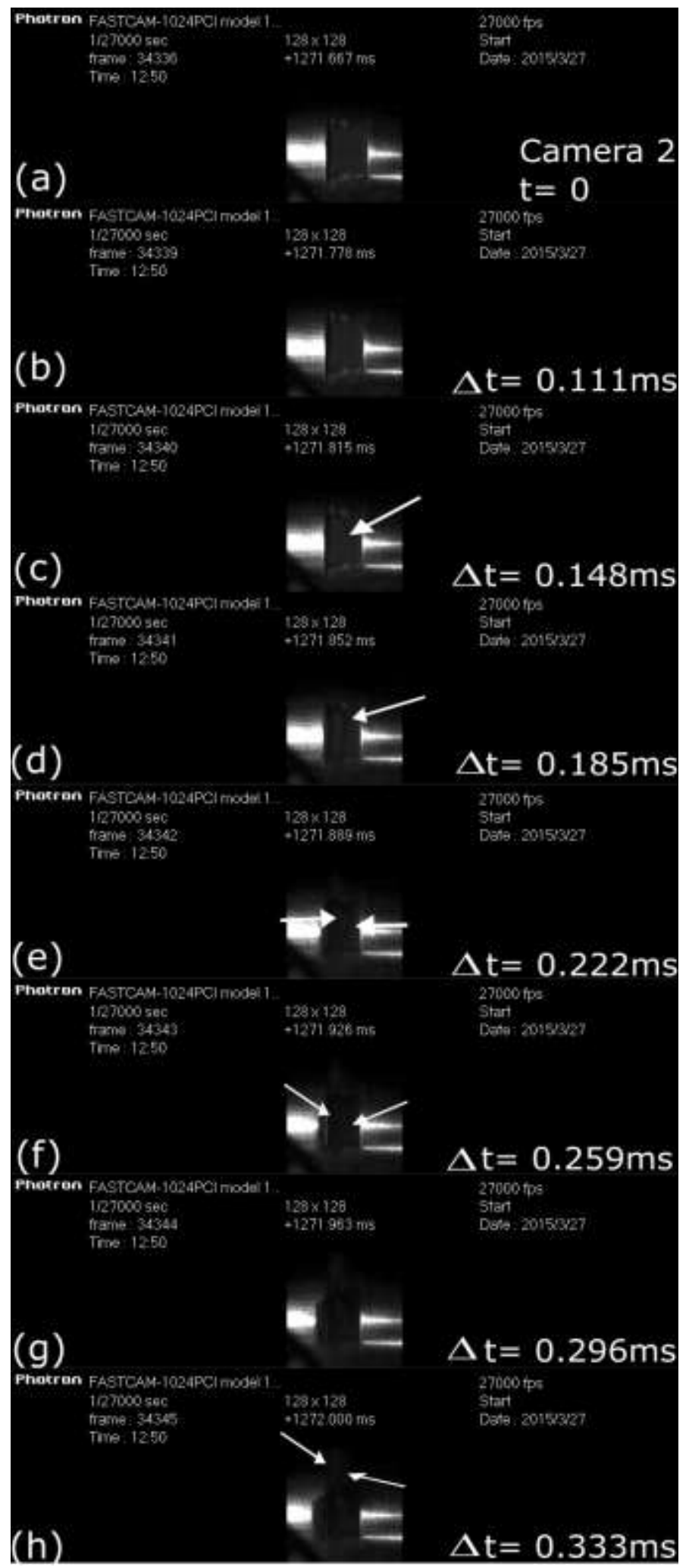

Figure 7. 


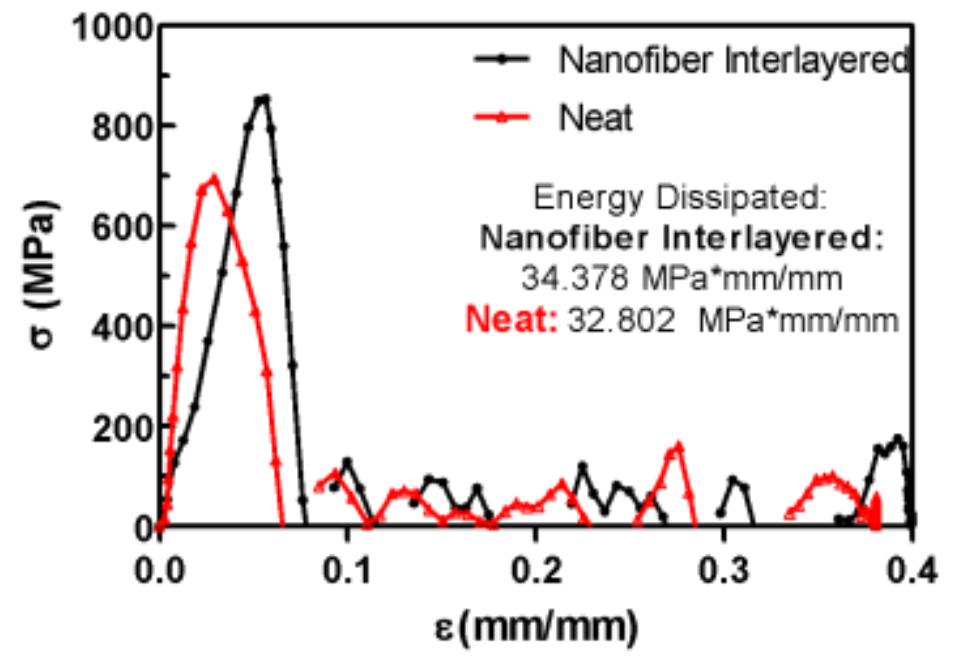

Figure 8. 
(a) Neat $(0 / 90) 25 \mathrm{~s}$ composites

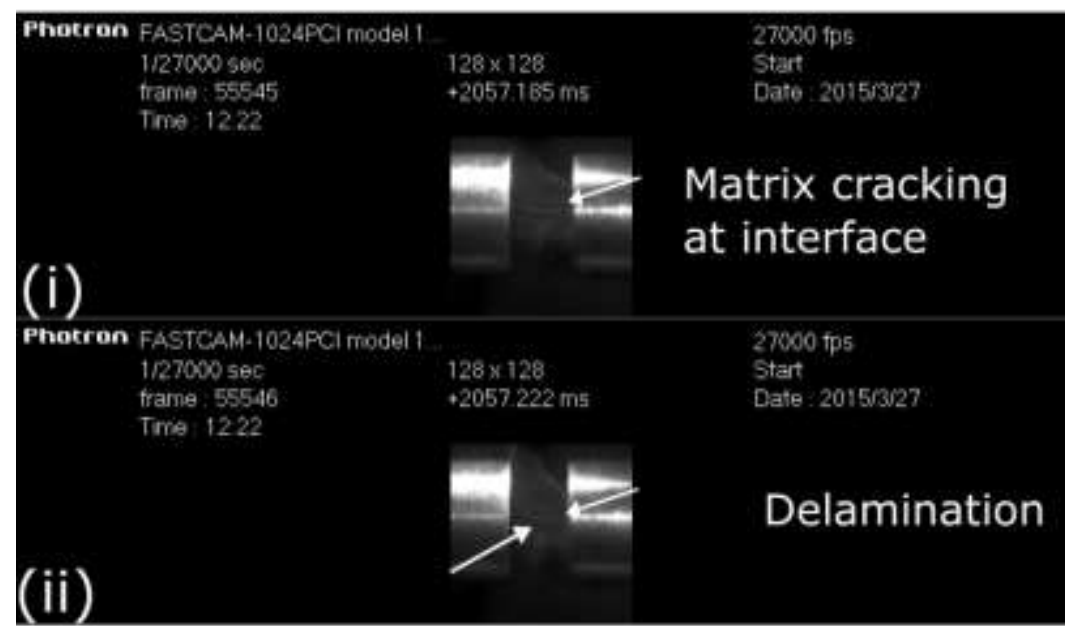

(b) Nanofiber interlayered (0/90/i)25s composites

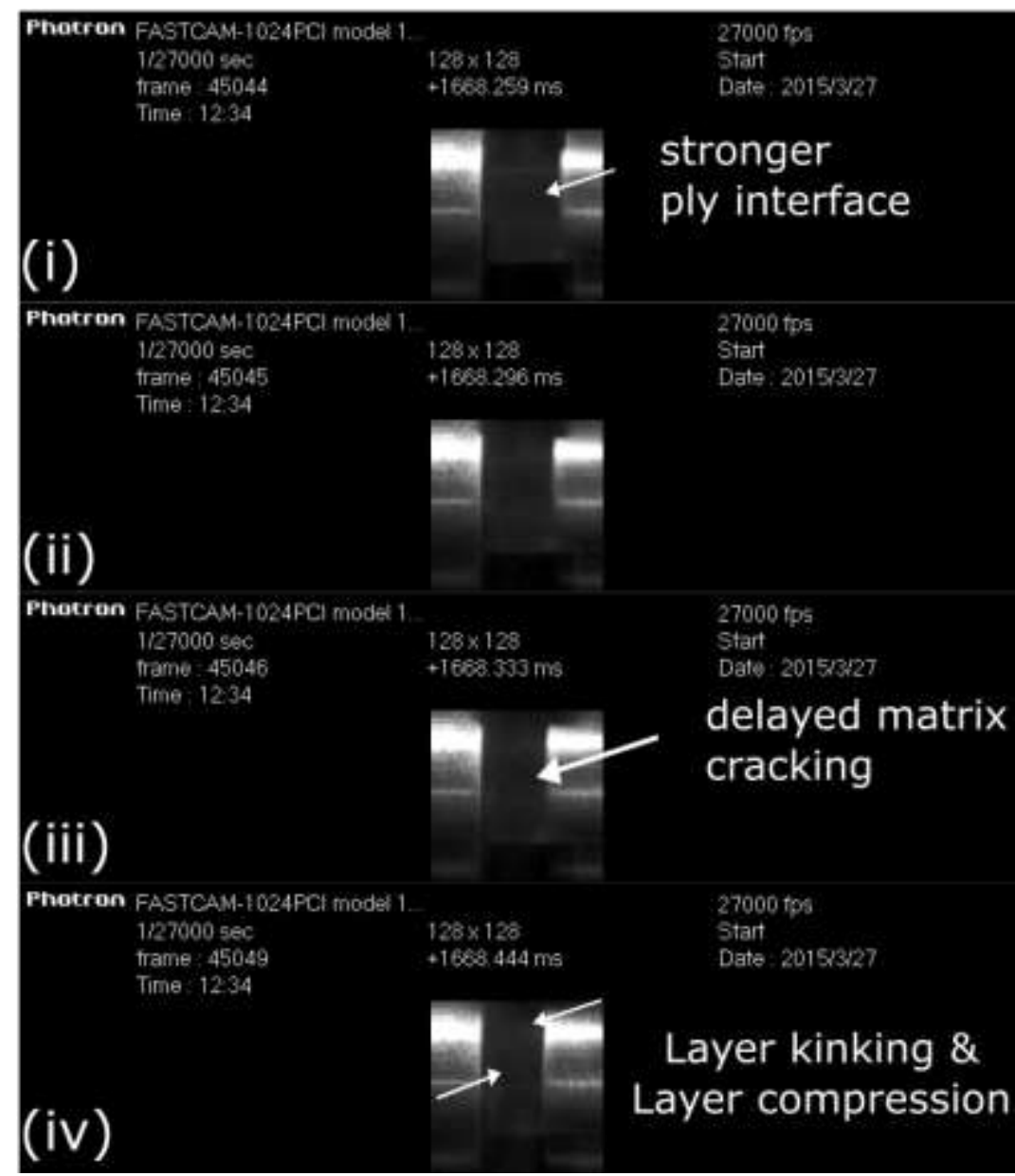

Figure 9. 

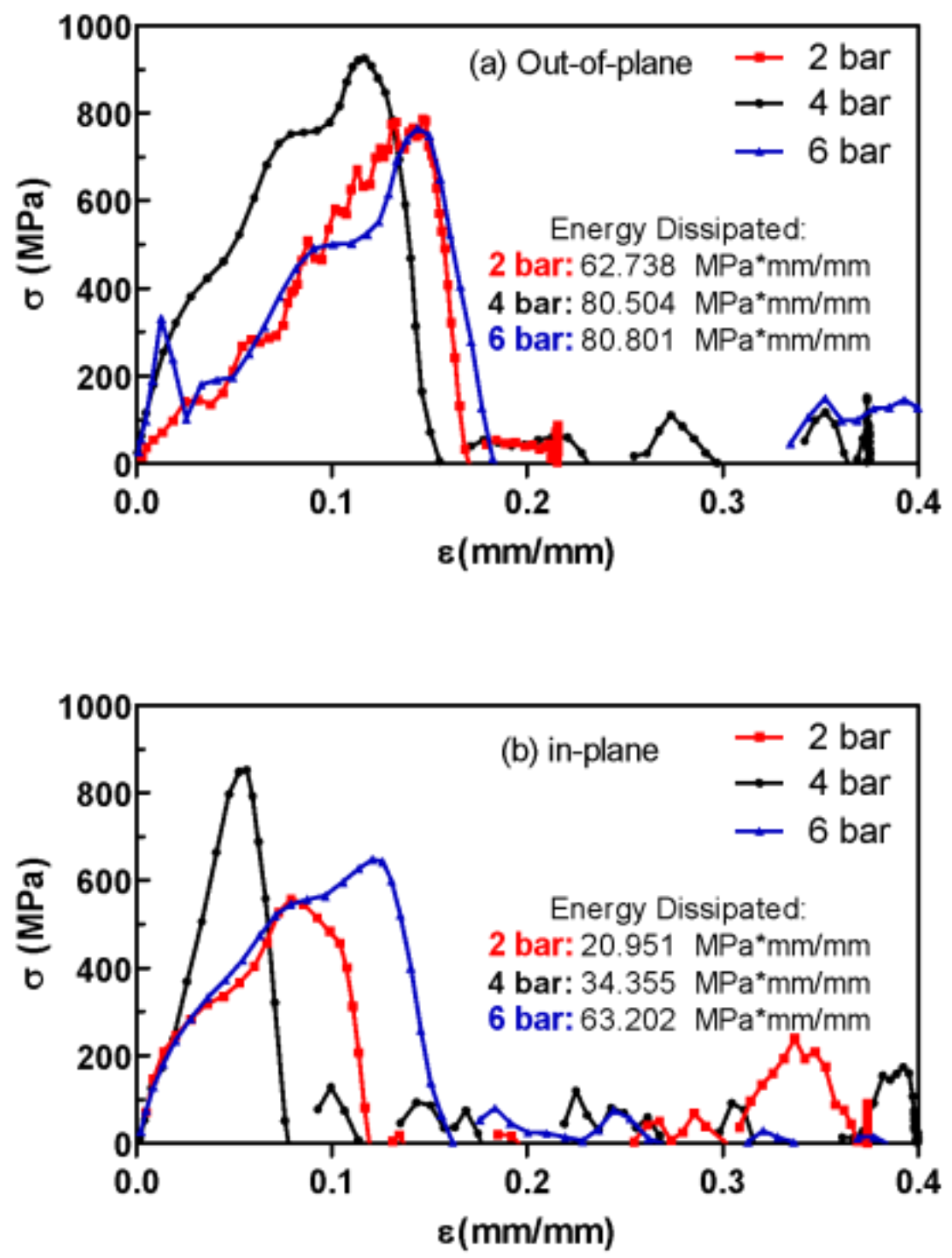

Figure 10. 


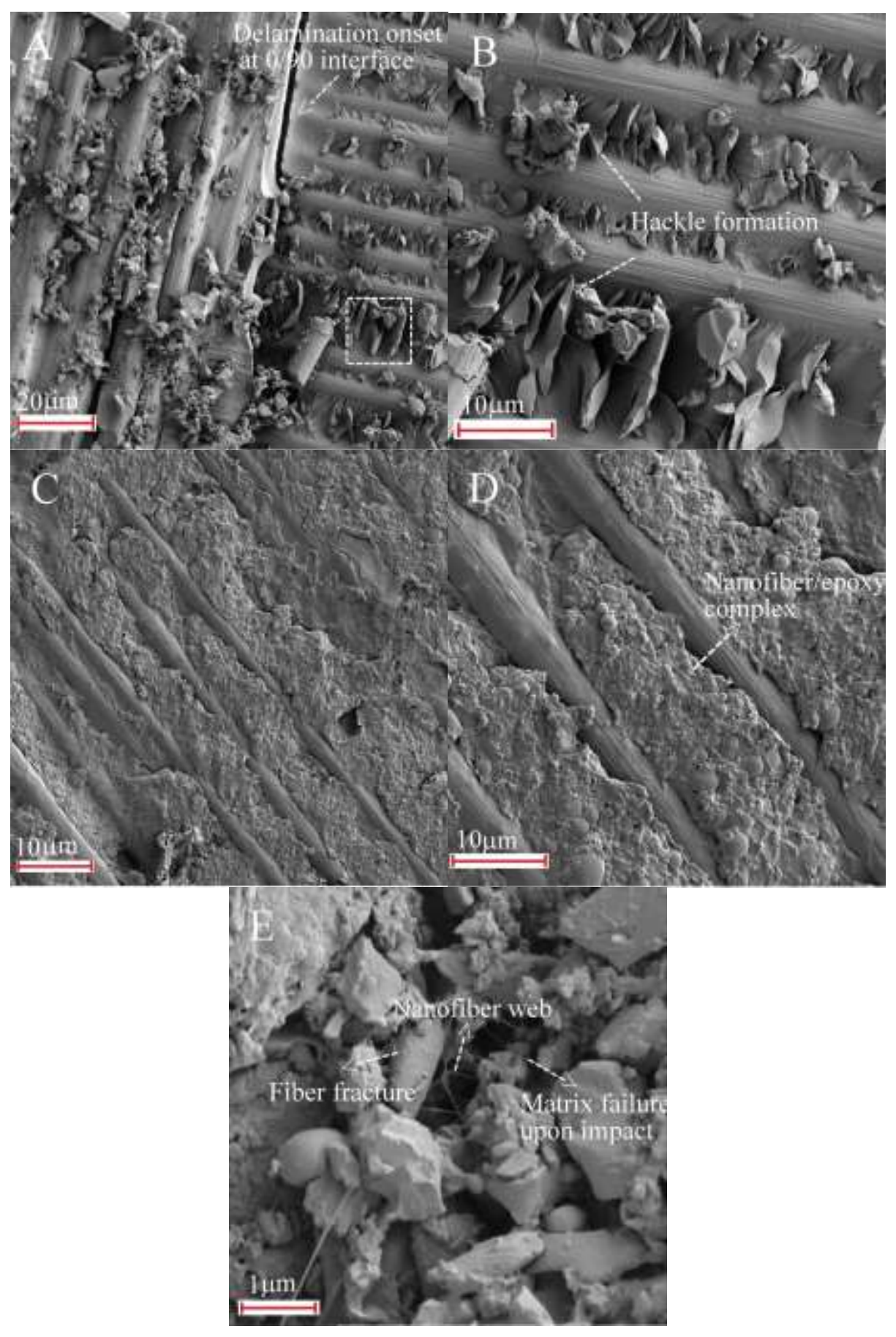

Figure 11 


\begin{tabular}{|c|c|c|c|}
\hline Specimen & Gas Barrel Pressure & $\begin{array}{c}\text { Ultimate Compressive } \\
\text { Strength (MPa) }\end{array}$ & $\begin{array}{c}\text { Dissipated Energy } \\
\left(\mathrm{MPa}^{*} \mathbf{m m} / \mathbf{m m}\right)\end{array}$ \\
\hline \multicolumn{4}{|c|}{ Through Thickness Loading } \\
\hline$(0 / 90)_{25 s}$ & 2 bar & $481 \pm 5$ & $45.2 \pm 3$ \\
\hline$(0 / 90)_{25 s}$ & 4 bar & $820 \pm 3$ & $71.6 \pm 3$ \\
\hline$(0 / 90 / I)_{25 s}$ & 2 bar & $788 \pm 5$ & $62.7 \pm 2$ \\
\hline$(0 / 90 / I)_{25 s}$ & 4 bar & $925 \pm 5$ & $80.5 \pm 2$ \\
\hline$(0 / 90 / I)_{25 s}$ & 6 bar & $766 \pm 8$ & $80.8 \pm 5$ \\
\hline \multicolumn{4}{|c|}{ In-plane Loading } \\
\hline$(0 / 90)_{25 s}$ & 2 bar & $524 \pm 5$ & $11.7 \pm 5$ \\
\hline$(0 / 90)_{25 s}$ & 4 bar & $606 \pm 5$ & $32.8 \pm 4$ \\
\hline$(0 / 90 / I)_{25 s}$ & 2 bar & $558 \pm 8$ & $21.0 \pm 6$ \\
\hline$(0 / 90 / I)_{25 s}$ & 4 bar & $852 \pm 8$ & $34.4 \pm 8$ \\
\hline$(0 / 90 / I)_{25 s}$ & 6 bar & $648 \pm 11$ & $63.2 \pm 11$ \\
\hline
\end{tabular}

Table 1 